fore the author suggests that it might advantageously be dropped in favour of such well-understood expressions as "reaction" or "orientation." It is satisfactory to find that he repudiates the endowment of the term "with mystical causal powers." By calling a reaction-say to light-a "tropism," one does nothing to explain it.

In his recent important work on the Foraminifera, Mr. E. Heron-Allen has directed attention to the purposeful behaviour shown by many of these Protozoa in the selection and arrangement of foreign materials worked into their tests. He sums up the evidence on this subject in a paper in the Journ, R. Microsc. Soc., vol. xvi., part 6 , and concludes "that there appears to be no organism in the animal kingdom, however simple be its structure, which lives a life of its own independently of any other organism, which is not capable of developing functions and behaviour... which in the Metazoa might be called, and would properly be so called, Phenomena of Purpose and Intelligence."

Turning from protozoa to insects, Mr. F. M. Howlett publishes (Bull. Entom. Research, vi., part 3, 1915) some puzzling observations on the chemical reactions of fruit-flies. In the genus Dacus, the males and not the females of certain species are strongly attracted by different eugenol-compounds, the smell of which resembles that emitted by plants that also attract the male flies. The corresponding females do not apparently enit similar odours, nor were they seen to frequent the odoriferous plants. Of the possible explanations suggested by Mr. Howlett, the most probable therefore seems to be that the smells are characteristic of some food which is attractive to males only.

\section{STUDIES IN MENDELISM}

$A \mathrm{~N}$ important paper on the inheritance of the A flowering time in peas and rice, by Yuzo Hoshino, has been published in the Journal of the College of Agriculture (Imp. Univ. Sapporo, Japan, vol, vi., part ix.). The author concludes that in peas the inheritance is governed by two pairs of Mendelian factors. In the one pair are lateness (dominant) and earliness (recessive); in the other pair are acceleration (dominant, hypostatic to lateness) and retardation (recessive, hypostatic to earliness). Gametic coupling between flowering time and flowering colour is also indicated, early red and late white flowers being equal in number and far fewer than early whites or late reds. The experiments on rice were not conclusive, but the author suggests that three pairs of Mendelian factors are probably concerned.

In the Proc. Amer. Phil. Soc. (vol. liv., No. 218) Bradley M. Davis discusses from the Mendelian point of view the mutation phenomena in CEnothera, and advises caution in accepting results based on breeding experiments where there is reasonable doubt as to the gametic purity of the parent "species."

The March number of the Journal of Genetics (vol. v., No. 3) contains several papers of interest. Misses C. Pellew and F. M. Durham find that from reciprocal crosses between Primula verticillata and $P$. floribunda plants resembling the female parent are generally obtained, these breeding true to type when self-fertilised. Occasionally the hybrids are of the $P$. Kewensis form, some partially sterile and others fertile. J. V. Eyre and G. Smith discuss some results from the cross-pollination of varieties of flax. W. Neilson Jones and Dr. M: Chevely Rayner contribute some important results from breeding experiments with two varieties of Bryonia dioica. The presence of waxy bloom on the ripe berry is a recessive character; the capacity to increase the number of vascular bundles in the stem beyond ten " behaves as a simple dominant to the absence of such capacity." The authors consider that their experiments "emphasise the need for caution in the subdivision of existing species without recourse to breeding tests." A supplement to Dr. L. Doncaster's well-known researches on the magpie moth (Abraxas grossulariata) is afforded by the $\mathrm{Rev}$. J. M. Woodlock, who discovered near Dublin a new variety of the moth, resembling lacticolor in pattern, but behaving as a simple recessive to typical grossulariata without any sex-limiting complication. The typical grossulariata pattern depends, according to Father Woodlock, on two dominant characters; the absence of one results in the appearance of lacticolor, that of the other in the appearance of the new variety, which the reverend author-perhaps with some reminiscence of literary criticism-proposes to designate as "Q."

\section{EFFECT OF TEMPERATURE ON SOILS.}

$T$ HE effect of temperature on some of the most important physical processes in soils has been studied experimentally by Mr. George J. Bouyoucos, of Michigan Agricultural Experiment Station, and his results are published as Technical Bulletin No. 22. Very few problems of this kind have been worked out experimentally. Our knowledge is based almost entirely on deductions from the laws of surface tension, viscosity, and expansion as affected by temperature. It is not surprising that when put to the test of experiment, under the complicated conditions that obtain in soils, these deductions are found wanting. When one-half of a column of soil of uniform moisture content is kept at $20^{\circ}$ or $40^{\circ} \mathrm{C}$., and the other at $0^{\circ} \mathrm{C}$., for eight hours, the percentage of water transferred from the warm to the cold soil increases in all types of soil with rise of moisture content until a certain water content is reached and then falls. The author terms the percentage of moisture at which this maximum transfer occurs, the thermal critical moisture content. The laws of capillarity and viscosity do not by themselves explain this result. Experiments on the movement of water vapour from warm to cold soil through an air space showed that such movement was insignificant under all conditions tested. The conclusion is drawn that the source of water as dew is not derived from the soil vapour, as commonly believed.

The translocation of water from a moist soil at $0^{\circ} \mathrm{C}$. to a dry soil at $40^{\circ} \mathrm{C}$. is very small. This has a most important bearing on the preservation of soil moisture by mulches. The study of the effect of temperature on the rate of percolation of water in soils showed that the rate of flow increases uniformly with rise of temperature only in the case of sand. In other soils, the rate of flow increases up to about $30^{\circ}$, and then falls. It is suggested that in the latter soils the swelling of colloidal matter closes the channels through which the water flowed. Although other reasons might be put forward to explain this effect, the author's hypothesis agrees with some of the known properties of colloids. Further, when the soil was tested at $20^{\circ} \mathrm{C}$., then at $50^{\circ} \mathrm{C}$., and again at $20^{\circ} \mathrm{C}$., the two readings at $20^{\circ} \mathrm{C}$. were not the same. This hysteresis effect is interesting.

The last section of the paper is devoted to the relation of temperature to soil aeration. The rate of flow of air through soil decreases with rise of temperature, and this effect is most marked in soils likely to contain colloidal matter, e.g. clays and peat. Although the author is, perhaps, rather too ready to assume that the views commonly held on many of the points arising from his work are inconsistent with his own deductions, this bulletin is a notable contribution to our knowledge of the dynamics of soils. 